\title{
Explotación de la temática de responsabilidad social de la publicidad dirigida hacia el hiperconsumidor: el caso Diesel
}

\section{Exploitation of the social responsibility theme of advertising directed towards the hyperconsumer: the Diesel case}

\author{
Benoit CORDELIER ${ }^{1}$ \\ Universidad de Quebec en Montreal \\ cordelier.benoit@uqam.ca \\ Pauline BREDUILLIEARD \\ Universidad de Quebec en Montreal \\ breduillieardpauline@hotmail.com
}

Recibido: 10 de septiembre 2013 Aceptado y Publicado: 24 de noviembre de 2013

\section{Resumen}

La publicidad alimenta y es el objeto de numerosos debates sociales. Las empresas acostumbran comunicar sobre sus valores sociales hacia sus públicos meta. Aquella integración les permite fabricarse una imagen de marca y aumentar su capital simpatía. No obstante, esta estrategia puede ser arriesgada y contraproductiva, sobre todo con. Empresas que escogen un tono de burla para tratar de temas serios. Frente a un consumidor crítico y conciente de los efectos negativos de su hiperconsumo, las empresas necesitant atender las esperas éticas y morales de la sociedad de consumo. Tomamos como ejemplos dos campañas publicitarias de la marca Diesel par evidenciar los límites de la integración de la dimensión ética en la comunicación publicitaria.

\section{Summary}

Advertising feeds and is the subject of many social debates. Companies usually communicate about their social values to their target audiences. That integration allows

\footnotetext{
${ }^{1}$ Los autores agradecen a Luisa Ithurbide por su ayuda esencial en el trabajo de traducción y revisión lingüística.
} 
them to build a brand image and increase their capital sympathy. However, this strategy can be risky and counterproductive, especially with. Companies that choose a tone of derision to deal with serious issues. Faced with a critical consumer and aware of the negative effects of their hyperconsumption, companies need to meet the ethical and moral expectations of the consumer society. We take as examples two advertising campaigns of the Diesel brand to show the limits of the integration of the ethical dimension in advertising communication.

Palabras clave: Comunicación, Consumo, Ética, Posicionamiento, Publicidad, Responsabilidad social.

Keywords: Communication, Consumption, Ethics, Positioning, Advertising, Social responsibility. 


\section{Introducción}

La publicidad permite comunicar un mensaje con contenido comercial, institucional e incluso social. En su mayoría, las empresas utilizan este medio con el fin de promover sus productos y servicios. Sin embargo, algunas aprovechan también la oportunidad para manifestar su opinión referente a asuntos de sociedad, de ecología y de desarrollo sostenible. El asunto del cambio climático es uno de los temas recurrentes presentes en publicidad.

Para numerosas empresas es de buen tono mostrar al público que les atañe el problema. Así es como, estamos cada día más y más expuestos a los mensajes procedentes de empresas que pretenden ser socialmente responsables.

En 2007, la marca Diesel recuperó estas interrogaciones en su campaña. Al analizar esta última, proponemos reflexionar sobre implicaciones y limites de su estrategia de comunicación.

Efectivamente, dicho caso presenta especial interés para cuestionar la trivialización de las temáticas de responsabilidad social en el marco de la publicidad comercial, el tono empleado y las modalidades de su integración en las estrategias de comunicación de marca. Consecuentemente, ello nos llevará a interrogarnos acerca de la legitimidad y hasta la moralidad de este tipo de estrategia. Sin pretender ser exhaustivos, desarrollaremos algunos aspectos relacionándolos con el consumidor hipermoderno de nuestra sociedad.

En una primera parte, hablaremos de la aparición de debates de sociedad en la publicidad. A continuación, tocaremos el tema de la evolución del consumo hacia el hiperconsumo. Luego, introduciremos los casos Diesel que alimentan nuestra reflexión y para terminar, presentaremos los límites de una crítica social en las comunicaciones marketing.

\section{La introducción de los debates de sociedad en la publicidad}

En lo referente al marketing, la meta principal de la publicidad es dar a conocer y vender los productos y servicios de las empresas. Sin embargo, en el transcurso del tiempo la simple propaganda se transformó en publicidad comercial y al final se introdujo en este medio cuestiones sociales, políticas y grandes causas humanitarias. De los años 50 a los 80, influenciada por algunos publicistas como Toscani, la 
publicidad cuyo fin era generar actos de compra llegó a ser una voz del debate societal.

Bernard Cathelat (1992, p. 18, nuestra traducción), en su libro Publicité et société, habla de este nuevo género así: "la comunicación publicitaria llegó a ser para muchos la solución de todos los graves problemas de sociedad que debemos enfrentar". Así es como en los años 80 nació un nuevo tipo de publicidad, se trata de la publicidad llamada social. Con ello, un lenguaje nuevo, un tono inusual integró la comunicación publicitaria. Las empresas no tardaron en posesionarse de la novedad para su publicidad institucional o gremial y así presentar sus valores para construir su capital de simpatía. Una de las primeras empresas utilizadoras fue a partir de 1982 Benetton y sus famosas campañas publicitarias con sabor social y moral (Tantet, 1992). Pasamos pues de una publicidad con fines comerciales a una publicidad moral y "humanista" que nos extrae de nuestra tranquila vida cotidiana y nos obliga a pensar.

Luciano Benetton con la ayuda de Oliviero Toscani supo introducir en sus publicidades los debates de sociedad de nuestra época empezando con la multietnicidad y pasando por cuestiones de tipo moral tal como la guerra, la religión, la pena de muerte, etc. La empresa dejó poco a poco la publicidad comercial a cambio de una publicidad más humanista que no temía enfocar los tabúes de nuestra sociedad por medio de la provocación.

Entonces fue en los años 80, más precisamente en 1984 cuando Benetton empezó a sacar publicidades en las que el producto desaparece poco a poco. En 1984, aparece el famoso slogan que todos conocemos United colors of Benetton. Este slogan se dará en distintos idiomas para luego quedarse con la terminología anglo-sajona facilitando así una mejor globalización de la marca. Como explica Tantet (1992) en sus trabajos, la elección de este slogan se funda en dos significados preciados por la empresa. Uno se califica como "significado literal" ya que representa la gama de colores y de productos Benetton, otro "humana", designa hombres, mujeres, niños de todos los países y colores de piel que llevan ropa Benetton. Este eslogan es una manera de guiño hacia el melting pot norte-americano. La empresa por medio de sus productos se reconoce como un lugar de enlace entre todas las etnias como se puede observar en sus primeras campañas que ponen de relieve las nociones de multietnicidad y de fraternidad. Aquellas primeras campañas definirán el nuevo modo de comunicación de la empresa y serán también sus tests de prueba referentes a la introducción en publicidad de temas más o menos tabúes. En 1989, el viraje será definitivo ya que casi siempre la empresa suprimirá en sus mensajes el producto para dejar lugar a temas de 
sociedad más políticos y sociales. Por fin, en los años 1991-92 es cuando aparece una suerte de ruptura entre la marca y el público. La marca deja de lado el registro de la unicidad y de la fraternidad que se puede calificar como políticamente correcto, para orientarse hacia temas más periodísticos y ligados con la actualidad (enfermedad, guerra, etc.) que intentan trasmitir la moralidad y hacer que nos demos cuenta que la publicidad debe mostrar el mundo tal como es (Tantet,1992; Teyssier, 2004).

Así, al eliminar el producto en sus mensajes y reemplazarlo por una puesta de relieve de la cultura de empresa y más que todo de su visión del mundo con una publicidad caracterizada a menudo como militante e incluso extremista, Benetton y Toscani, mediante su técnica publicitaria inventaron para la empresa una imagen personal exclusiva (Tantet, 1992). Preciada, pero frecuentemente criticada por la brutalidad de sus imágenes y de sus disparates o sinsentidos en relación con el papel inicial de la empresa, la publicidad Benetton supo traer al escenario público los debates de sociedad. Varias campañas suyas fueron galardonadas con motivo de concursos publicitarios. Entonces aún cuando podían alterar el orden establecido de la profesión y de nuestra sociedad, se les reconocía calidad en cuanto a creatividad (Teyssier, 2004).

¿Mas utilizar enfermedades, guerras (...) para vender jerseyes y de manera indirecta dar que hablar de sí era o no era una postura ética? Para Benetton y Toscani no se trataba de vender jerseyes sino de dar a conocer un mensaje sobre el libre albedrío de cada quien y sobre lo que ocurre en el mundo (Toscani, 1995). También era para la empresa una manera de alcanzar una dimensión universal (Tantet, 1992). Mientras para las diferentes asociaciones de defensa, el público, algunos gobiernos y el organismo de autorregulación de la publicidad de la época (en Francia, bureau de la vérification de la publicité, BVP), se trataba más bien de una intención no ética, no moral para dar que hablar de sí y vender (Teyssier, 2004). Como lo menciona Reuter (1994), muchos dijeron que Benetton explotaba la miseria y el sufrimiento humano con fines comerciales. En contextos comerciales, el margen entre sensibilizar al público sobre problemas de sociedad y su instrumentalización cínica con fines consumeristas es tenue.

El modo de comunicación de Benetton, provocando con imágenes impactantes, obligó los medios de la publicidad a interrogarse sobre la misión y el papel de la publicidad (Teyssier, 2004). Debía seguir idealizando nuestro mundo o al revés ser el lugar de difusión para mensajes más políticos y sociales? A su modo, Benetton abrió el camino hacia una reflexión sobre el papel verdadero de la publicidad y de las profesiones con ella relacionadas. Pero como lo menciona Dominique Quessada (2002), introdujeron 
los debates de sociedad en la publicidad: "chocando con imágenes violentas, pretender llegar a ser un sitio para el debate publico y así producir una toma de conciencia que los medios de comunicación hoy en día no llevan a cabo."

Así, las campañas publicitarias de Benetton impulsaron los organismos de regulación a tener más cuidado y a ahondar su cuestionamiento sobre lo que es ético o no hacer en el universo de la publicidad (Teyssier, 2004). Según Ricoeur (1991), el enfoque kantiano permite definir la moral. Pone por delante una noción de deber y de obligación de la norma. Por consiguiente, la moral simboliza las normas es decir lo que está permitido y lo que está prohibido, tomando a la vez en cuenta la noción de obligación referente a la relación de una persona a las normas (Ricoeur, 2001).

A raíz de la teoría de Kant ya que la acción prevalece sobre las consecuencias, las bases de la ética publicitaria fueron asentadas (Pratt \& James, 1994). La ética debe entonces permitir tener una conducta que no sea de ninguna manera perjudicial para los demás. Sin embargo, para muchos, parece difícil unir ética y negocios pues estos términos parecen contradictorios ya que lo primero que busca una empresa es acrecentar sus ganancias. Aunque parezca difícil, Gilles Lipovetsky (1993) indica que es posible unir estas dos nociones y que se puede observar en publicidad tomando el ejemplo de Benetton :

La articulación entre ética y business choca al público. Al contrario considero que es un progreso respecto a publicidades que eran alienantes y embrutecedoras. Estos restos de moralismo que, al decir que Benetton explota los buenos sentimientos con fines de ganancia, ponen obstáculos a la experimentación. Esta publicidad se atreve y la gente se pregunta acerca de lo que es la publicidad. Ya no proporciona el sueño, es una clase de mensaje totalmente conforme con nuestra sociedad. (Libération, octubre 1993, citado por Teyssier, 2004, nuestra traducción)

Sin embargo, si seguimos con este ejemplo, no podemos ignorar que estas publicidades hicieron que se hablara de Benetton gratuitamente y le ayudaron a inscribir el nombre de Benetton en la mente del público. La frontera es tenue entre el objetivo ético y moral de un mensaje publicitario y su esencia que es vender.

\section{Del consumo tradicional al hiperconsumo}

Gilles Lipovetsky (2006) distingue tres edades de la sociedad de consumo que nos llevan hacia el consumidor hipermoderno. 
La primera fase va de la industrialización hacia la sociedad de producción de masa. El volumen y los precios bajos son las llaves del comercio. La necesidad de estimular las ventas para mercados que llegan a saturar refuerza el papel del marketing que va a crear una economía de marcas. Estas permiten iniciar el proceso de desintermediación en la relación entre productos y consumidores. La marca permite crear en primer lugar confianza. Esta última descansa en las calidades materiales del producto que van a ser garantizadas por la firma comercial del fabricante. El producto ofrece un Unique Selling Purpose, otra apelación para iniciados, para lo que es una promesa hecha al consumidor, una primera señal de seducción. "La fase I inventó el consumo-seducción, el consumo-distracción del cual somos herederos fieles." (Lipovetsky, 2006, p. 29, nuestra traducción).

La segunda fase de la sociedad de consumo se desarrolla de los años 50 a 80 y asienta las lógicas de la primera fase intensificando las modalidades de distribución. La estructura de consumo evoluciona: la parte de bienes de consumo domésticos disminuye en provecho de bienes de equipo que a su vez dejarán lugar a productos que dependen de la lógica efímera de la moda. "En la fase II, se deshacen a toda velocidad las antiguas resistencias culturales frente a las frivolidades de la vida material comercial." (Lipovetsky, 2006, p. 33, nuestra traducción). Los mecanismos de la seducción y del hedonismo derrumban los rigores de una planificación del consumo individual y colectivo orientado hacia el porvenir en beneficio del goce cotidiano.

La fase III de la sociedad de consumo es para Lipovetsky la del regreso de la conciencia. La crisis post choque petrolero y el materialismo de los años 80 dificultaron la crítica ecologista de los años 70. El consumidor la descarto en beneficio de la individualización del consumo y de la búsqueda de los correspondientes placeres. Regresa poco a poco desde los años 90, y trabajos como el famoso No Logo de Naomi Klein (2000) popularizan un nuevo modo de considerar nuestro consumo. Los consumidores occidentales deben darse cuenta que su consumo descansa en sistemas de producción globalizados que no corresponden con sus valores éticos o por lo menos con una idealización de estos últimos. El consumo ya no es entonces un goce sino una señal dada en el marco de una sociedad globalizada, dentro de un planeta compartido. Para Lipovetsky, la disponibilidad importante de la información obligaría el individuo a tener un consumo ético y responsable. Sin embargo, no se ilusiona: el distanciamiento de las personas con su consumo, su reflexividad no es ni regular ni constante. 


\section{Publicidades y trivialización de los desafíos sociales: el caso diesel}

Estos últimos años, la problemática social que a menudo encontramos en la publicidad es el desarrollo sostenible, el calentamiento global y la responsabilidad social de la empresa sobre el tema. Uno de los casos más conocidos es la campaña publicitaria de Diesel en 2007. Su slogan era Global Warming Ready. Dio mucho que hablar pero aun cuando ganó el gran premio de la prensa magazine este mismo año (Audouin, Courtois y Rambaud-Paquin, 2009), así como el León de plata para las campañas impresas en el festival de publicidad de Cannes, siempre en 2007. El principal reproche que se le hace es la denegación y la trivialización del calentamiento global mediante la promoción de ropa adaptada al cambio climático.

Al observar más detenidamente estas publicidades, vemos como los jóvenes presentes llevan ropa Diesel y aparentan estar felices y no preocuparse por los cambios sufridos en su alrededor. En las distintas publicidades, los rostros y ademanes de los personajes ostentan expresiones alegres y desenfadadas. Parece que no notan los cambios climáticos pues no han influenciado sus actividades. Muy al contrario, la publicidad causa la impresión de que el calentamiento climático no es tan temible ya que podremos siempre seguir con nuestras actividades cotidianas y conservar un aspecto de moda gracias a Diesel. Si tomamos por ejemplo la publicidad representando el Campo de Marte, en Paris cubierto por una vegetación frondosa parecida a la selva amazónica, observamos que los tres protagonistas parecen integrar perfectamente el nuevo entorno ya que entre ellos uno pasea una iguana atada como si fuera un animal doméstico. Otro ejemplo, Rio de Janeiro bajo las aguas, aquí también la joven pareja parece totalmente despreocupada. En el segundo plano, la estatua de Cristo sólo sale la cabeza del agua. Parece que la ciudad entera está inundada. No es ninguna molestia para los dos jóvenes ya que en el primer plano se ven acomodados en el puente de un yate. La joven está tomando el sol, luce una sonrisa y parece estar feliz mientras el joven sentado en el borde del yate proyecta agua por la boca hacia ella. Los dos disfrutan de su jueguito sin fijarse en la ciudad inundada. La campaña en su conjunto presenta situaciones parecidas. Aunque los lugares se hayan transformado (Nueva York inundada, la plaza San Marco invadida por papagayos en vez de pichones, la muralla de China enarenada, el Monte Rushmore vuelto playa, el Antártico estación de veraneo para chapotear con pingüinos, etc.), los jóvenes se han adaptado o incluso casi no han cambiado su modo de ser ya que llevan la ropa adecuada para enfrentar el cambio.

Cada cartel está marcado con el eslogan de la campaña Global Warming Ready (listo 
para el calentamiento global). Este eslogan pone de relieve el mensaje de la marca que parece decir con la ropa Diesel, estaremos listos para (sobre)vivir al calentamiento climático. Una clase de tarjeta postal que es la presentación de la aclimatación al cambio climático.

Así una interpretación posible de esta campaña sería de no ser la promoción de un modo de vida egoísta y sin respeto de las preocupaciones climáticas presentes en nuestra sociedad, por lo menos la trivialización y la desdramatización de éstas.

Gran parte del publico interpretó de este modo estos carteles. Muchos no entienden el posicionamiento de Diesel en esta problemática, pues parece que la empresa trivializa el cambio climático en vez de impactar positivamente los consumidores concientizándoles.

La pregunta puede ser si es que Diesel escogió el humor negro y la denegación del problema precisamente para chocar y suscitar la reflexión.

Según el Concejo de la Autoridad de Regulación de la Publicidad en Francia (ARPP) (ex BVP), esta publicidad ha sido juzgada fuera de lugar e inoportuna porque induce los jóvenes en error difundiendo un mensaje que al parecer, sugiere que el calentamiento climático no es tan preocupante y que basta con llevar ropa ligera para enfrentarlo. Así la marca trivializa la problemática presentando conductas que no son eco-ciudadanas.

Esta campaña trivializa e incluso relativiza el tema del cambio climático. Así es cómo va en contra de numerosos esfuerzos de movilización ciudadana entablados por los poderes públicos. Es pues especialmente inoportuna. (de la página Web de la ARPP, 30 de enero de 2007).

Y también, se difundió cuando el asunto de la comunicación responsable de las empresas y del respeto del medio ambiente se comentaba mucho con motivo de los distintos convenios y cumbres (Grenelle de l'Environnement - 2007-, la Charte d'engagements pour une communication responsable par l' Union des Annonceurs UDA, en 2007 - etc).

A continuación de esta campaña, l'ARPP pidio al anunciante detener la difusión. Se quitaron los carteles sin embargo la plataforma Internet y la publicidad video siguieron circulando.

La empresa Diesel es familiar, cliente de las publicidades provocativas y porno-chic como se ha visto en sus anteriores campañas. $Y$ en este caso, va todavía más lejos 
mezclando de manera desenvuelta una sensualidad común y corriente en esta clase de comunicación con la gravedad de desafíos climáticos que son la consecuencia de las modalidades de producción de nuestra sociedad de consumo.

Por su parte, Diesel afirma que es más que todo una empresa de ropa de confección y que, desde el inicio, tocó los temas de sociedad en sus publicidades. Con la campaña Global Warming Ready, precisa que no buscaba inculcar malos valores a los jóvenes sino que podría tal vez provocar la reflexión sobre el tema :

A lo largo de los años, las campañas publicitarias de Diesel abordaron varias problemáticas globales, usando un estilo radical, a menudo surrealista. El año 2007 empieza con una campaña que subraya los riesgos que conoce el planeta por el calentamiento climático. Solamente somos una compañía de ropa de confección y no pensamos que se puede cambiar el mundo con una campaña, pero si nuestro tono no convencional y la fama de la marca pueden detener la atención de la gente más duraderamente que un boletín de noticias, darles que pensar sobre las consecuencias de nuestras acciones y la responsabilidad de cada quien, entonces algo se habrá cumplido. (www.diesel.com). (citado por Dispa, 2009)

Además, Diesel se comprometió ecológicamente al decidir verter el 10\% de la colección presentada en su publicidad a la asociación de Al Gore (Stop global warming) y sacó un cartel para promover la compra del DVD de Al Gore y la visita de la página Web de la Asociación (Dispa, 2009). El objetivo de dicha colaboración era mobilizar a la gente.

Con esta campaña, Diesel aborda una problemática social hoy en día muy importante. Sin embargo, el tratamiento que le da puede ser discutible y ser mal interpretado ya que hacer burla de la problemática no sea tal vez la solución. Así, el ruido mediático acerca del carácter provocativo y ligero de la campaña dio que hablar de la empresa y del calentamiento climático. Sin embargo, para este caso como para la publicidad Benetton, vale preguntar si esta clase de publicidad es o no ética, si es equívoca o no para el consumidor.

Observamos también que desde sus inicios la empresa Diesel opta por la burla y la frivolidad. Se dio a conocer por su ropa pero igualmente por sus campañas publicitarias provocativas y desfasadas. En 2010, Diesel conserva la misma estrategia para su campaña Be Stupid, en la cual la marca instiga al público a tomar riesgos. Mediante, esta campaña de tono provocativo, Diesel presenta sus productos con jóvenes que se encuentran en situaciones surrealistas y estúpidas, e incluso peligrosas. Los carteles 
vienen acompañados con textos así : "Only the stupid can be truly brilliant", "Smart plans. Stupid improvises" o también "If we didn't have stupid thoughts, we'd have no interesting thoughts at all". Estas publicidades vienen firmadas con el eslogan Be stupid y el logo Diesel. De modo que la marca tal vez promueva indirectamente un estilo de vida peligroso pero más que todo parece decir a los jóvenes : "Si son Diesel, es porque no se dejan influenciar por esta sociedad aburrida y que saben llevar una vida excitante haciendo locuras, fuera del sentido común". Con la ayuda de sus mensajes populistas, Diesel, tal un mal estudiante, maltrata los valores de la sociedad promoviendo la realización de acciones estúpidas y denigrando cualquier forma de sabiduría. Su dialéctica de pseudo-rebelión opone por una parte la efervescencia y el individuo y por otra la sociedad y el aburrimiento.

En oposición a Benetton, Diesel trata los temas y los valores de nuestra sociedad de modo desfasado y frívolo y su comunicación parece vacilar entre su papel básico que es hacer que sueñe la gente comprando ropa de moda y un papel posible en la concientisación del público para los problemas de sociedad. Efectivamente, como observamos en la anterior cita en el caso de las publicidades Global Warning Ready, aunque la empresa pretende solo vender ropa sin buscar modificar el comportamiento de la gente, se contradice en el mismo párrafo mencionando que siempre ha comunicado con base a las problemáticas globales que afectan nuestra sociedad. Y que si su estilo puede llamar la atención de la gente sobre el tema entonces habrá servido de algo.

\section{Límites de una crítica social en las comunicaciones marketing}

En fin de cuentas, para tomar la expresión de Lipovestky, el discurso ecológico no es el de una pasión revolucionaria sino uno de los instrumentos de evaluación y reafirmación de un consumismo que con más o menos fuerza quiere ser responsable. Tocó la hora de una toma de conciencia sin renunciamientos. El discurso publicitario es tranquilizador y promete en un primer tiempo una biodegradabilidad de $99 \%$. Y luego como ya observamos se quiere participar en los debates de sociedad. Con este fin emplea imágenes choc a la Toscani. Pero si las campañas Benetton, favorecen las imágenes provocativas con poca (por no decir inexistente) conexión con los productos de la marca, no sucede lo mismo con las siguientes campañas como la de Diesel que presentamos anteriormente. En la estrategia de Benetton, es el tema tabú, o acaso la estrategia marketing que serán el objeto central del debate de sociedad, en la 
estrategia Diesel el drama ecológico se desarrolla en el segundo plano mientras en primer plano se mueve una juventud sensual y desenfadada. Ya no es la promoción del debate de sociedad sino la del sueño sobre el cual se erigen las comunicaciones marketing del consumismo-seducción. En lo que Lipovetsky llama fase III, la publicidad "toca todos los registros" (Lipovetsky, 2006, p. 161) incluyendo el desfase y la impertinencia. Busca nuevas rutas para comunicar con un consumidor muy al tanto de las técnicas de comunicación, hastiado, repleto. $Y$ busca conectarse mediante el espectáculo y la emoción; "[...] la publicidad hipermoderna no busca tanto la celebración del producto sino la innovación, la emoción, la distracción, el rejuvenecimiento de la imagen, llamar la atención del consumidor" (Lipovetsky, 2006, p. 165). No busca pues cambiar el mundo. Podríamos quedarnos en esto y concluir que Diesel está en su papel.

Sin embargo, el caso Diesel es interesante y pide ser profundizado pues el malestar que suscitó nos conduce a interrogarnos sobre límites de la participación de la comunicación publicitaria en el debate público. Se la ha culpado de ser una herramienta de aculturación a la sociedad de consumo. Más recientemente, se la ha tachado de instrumento posible del greenwashing. El malestar surge del hecho que la publicidad, durante mucho tiempo reconocida como simple instrumento de promoción removiendo los elementos afectivos y cognitivos que pueden vincular el producto y el consumidor, ahora pretende abiertamente difundir mensajes que mueven valores e ideologías vinculados con debates de nuestra sociedad en general (Lipovetsky, 2006) y en el caso que nos ocupa, la ecología y la responsabilidad social. ¿Desempeña todos los registros pero le conviene hacerlo en una sola campaña? ¿Puede una marca integrar, sin consecuencia dañina, dos registros antitéticos en un mismo posicionamiento? El BVP (ahora ARPP) condena. El ruido mediático obliga Diesel a justificarse dando entrevistas. So capa de una finalidad inicial comercial cuyas herramientas para alcanzarla son la estetización y la emoción, los voceros de la marca buscan a la vez relativizar la fuerza del alcance deresponsabilizante de su mensaje queriendo a la vez hacernos creer que este último puede contribuir al debate publico y por otra parte para adecuar su discurso con la finalidad moral de su campaña, la empresa busca, como diría Lipovetsky (1992, p. 336), "darse alma [...] gracias a la lógica del donativo y de la benevolencia" contribuyendo a la fundación Stop Global Warming de Al Gore.

¿Mas son estas acciones suficientes? Sin dar realmente una respuesta, observamos que la marca sigue comunicando con este mismo estilo impertinente. Su campaña de 
2010, Be Stupid, con fuertes matices surrealistas, se libera de cualquier posibilidad de justificación políticamente correcta. La verdadera coherencia de esta marca no aparece en la participación al avance de un debate público sobre ecología o responsabilidad social. En realidad, se sitúa en la imagen pica pica al compás de una sociedad individualista y narcisista que en lugar de una solemnidad ideológica prefiere una puesta a distancia frívola y humorística (Lipovetsky, 1983, 2006; Lipovetsky \& Charles, 2004).

\section{Conclusión}

Diesel participa a una clase de trivilización de los desafíos de la sociedad. Esto funciona pues la marca está en resonancia, conforme con un público que no se siente aludido por estos debates o que los desvincula de sus acciones de consumo. En Inglaterra, la Advertising Standards Authority (ASA), organismo que equivale a la ARPP francesa condenó con motivo de la campaña de 2010 Be Stupid este tipo de estrategia y la calificó como "asocial":

However, we noted the image in poster ad (b) appeared realistic and considered that the image portrayed socially challenging actions that might be attracttive to hounger consumers who would be interested in the youthful and edgy fashion rangez and might encourage behaviour that was anti-social or irresponsible. (página web ASA, 30 de junio).

Sin embargo, el uso de esta estrategia « asocial » sin complejos muestra que da resultados ya que ganó el León de oro en la categoría Grán premio en el festival de la publicidad de Cannes en 2010.

Así, incluso cuando tenemos una condena de las instituciones rigoristas, en paralelo existe una celebración de estas realizaciones por la industria glamour mediante sus festivales y concursos.

Por consiguiente, si regresamos hacia nuestras preguntas podemos contestar así: ¿refleja la estrategia de Diesel una preocupación ética? No lo creemos así. ¿Funcionan sus campañas? Parece que sí. La única dificultad fue con la campaña Global Warning Ready al pretender tener un compromiso social. Las siguientes campañas dejaron a un lado esas precauciones y su estrategia aparecieron entonces más coherente.

Podemos concluir fríamente que, de un punto de vista marketing, es preferible conservar un posicionamiento simbólico y semiótico coherente. Si la marca escoge la 
provocación y la frivolidad, no debe perderse en justificaciones.

Aunque solo hemos observado el caso Diesel, este último es coherente con los análisis sociológicos y filosóficos de Lipovetsky. Sin embargo, no hay medida o identificación de un punto de ruptura más allá del cual el contrapié de la posiciones éticas y morales daña las acciones marketing y comerciales. Así por interesantes que son las reflexiones basadas en el caso Diesel, las conclusiones que sacamos no permiten una operacionalización clara y sencilla de lo que tendría que ser un posicionamiento semiótico coherente. La evolución de la sociedad y la voluntad que puede existir de integrar o no una dimensión ética a una marca lo dificulta.

Para terminar, notaremos que más allá de una estrategia empresarial/instrumental al final bastante cínica, incluso sin tener una estrategia ética, la marca al participar a la construcción de una representación del mundo, contribuye o sea a promover los debates de la sociedad o sea a alimentar la indiferencia o el desprecio hacia ellos. 


\section{Bibliografía}

Cathelat, B. (1992). Publicité et société. Paris: Payot (1e éd. 1987).

Dispa, M. (2009). Quand la publicité dépasse les bornes? DIESEL prêt pour le changement climatique. Éthique et économique/Ethics and Economics, 6(2).

Lipovetsky, G. (1989). L'ère du vide. Essais sur l'individualisme contemporain. Paris: Gallimard (rééd. poche, « Folio » 1983; 1989).

Lipovetsky, G. (2000). Le crépuscule du devoir. Paris: Gallimard (1e éd. 1992).

Lipovetsky, G. (2002). Métamorphoses de la culture libérale - Éthique, médias, entreprise. Montréal: Éditions Liber.

Lipovetsky, G. (2006). Le bonheur paradoxal. Essai sur la société d'hyperconsommation. Paris: Gallimard.

Lipovetsky, G., y Charles, S. (2004). Les temps hypermodernes. Paris: Grasset (rééd. Poche 2006).

Pratt, C. B., \& James, E. L. (1994). Advertising Ethics: A Contextual Response Based on Classical Ethical Theory. Journal of Business Ethics, 13(6).

Quessada, D. (2002). L'esclavemaître. L'achèvement de la philosophie dans le discours publicitaire. Paris: Éditions Verticales/Le Seuil.

Reuter. (1994, 16 de febrero). "Benetton fait encore de la vague", Le journal de Québec, p.20.

Ricœur, P. (1991). Éthique et morale. In P. Ricœur (Ed.), Lectures 1 - Autour du politique (pp. 256-269). Paris: Seuil.

Ricœur, P. (2001). De la morale à l'éthique et aux éthiques. In P. Ricœur (Ed.), Le Juste (pp. 55-68). Paris: Éditions Esprit.

Tantet, M. (1992). La stratégie publicitaire de Benetton. Communication et langages. 94(4), 20-36.

Teyssier, J.P. (2004). Frapper sans heurter - Quelle éthique pour la publicité ?. Paris: Armand Colin.

Toscani, O. (1995). La pub est une charogne qui nous sourit. Paris: Éditions Hoebeke. 


\section{Forma de citar este artículo en bibliografías}

CORDELIER, B. y BREDUILLIEARD, P. (2013) "Explotación de la temática de responsabilidad social de la publicidad dirigida hacia el hiperconsumidor: el caso Diesel" se encuentra publicado en Revista PANGEA (ISSN: 2172 - 3168); Año 2013, $N^{\circ} 2$, en páginas 56 a 71 . Red Académica Iberoamericana de Comunicación. Recuperado el__ de___ de 2 __ de: http://www.revistapangea.org 